\title{
TRANSFORMING CULTURAL BARRIERS INTO ASSETS: LESSONS LEARNED FROM A AGLOBAL INSURANCE BROKER
}

\author{
Elena LVINA ${ }^{1}$ \\ Alex MATVEEV ${ }^{2}$ \\ George GRISHIN ${ }^{3}$
}

\begin{abstract}
This study provides a refined look at the challenges in crosscultural communication and contributes to our understanding of the key skills and behavioral factors that explain and increase employee intercultural competence. In a qualitative investigation, we explored both the "whats" and "hows" in the communication of interculturally competent employees of a global insurance broker - Oakeshott Insurance -working in the UK and Ukraine. We found that interculturally effectiveness depended on employee ability to shift their frame of reference and to actively seek culturally diverse experiences. Contrary to previous research, frequent exposure to different cultures and the length of employment in a multicultural organization did not correspond to the highest level of intercultural sensitivity. We recommend that global organizations mitigate the legislative and language barriers and further develop the intercultural competence of employees by focusing on the cultural and societal context and actively
\end{abstract}

Keywords: Intercultural Competence, the United Kingdom, the Ukraine, MNC, Oakeshott Insurance

JEL classification: F23, M12

DOI: $10.24818 /$ RMCI.2019.3.226

\section{Introduction}

A sense of urgency and criticality in understanding a different culture has been growing since the fall of the Iron Curtain when new market opportunities started to present themselves at previously unseen rates. This awareness continued to grow profoundly with new players representing emergent economies, entering the world market soon after. Obvious language differences were multiplied by not-

1 Elena Lvina, Saint Joseph's University, Haub School of Business, USA, E-mail: elvina@sju.edu, Telephone: 1610660 2240, Fax: 6106601229

2 Alex Matveev, College of Staten Island, CUNY, USA, Telephone: 718982 2955, E-mail: amatveevcuny@hotmail.com

3 George Grishin, Oakeshott Insurance, UK, Telephone: 44776844 4824, E-mail: George@oakinsur.com 
so-obvious differences in cultural values and in the assumptions of how the business should work, leading to multiple cases of miscommunication, a loss of potential business opportunities, and, often, crashes of newly formed cross-border joint ventures. Interestingly, national culture per se has not been identified as a major cause of these failures (i.e., Ho Park and Ungson, 1997; Pothukuchi, Damanpour, Choi, Chen and Ho Park, 2002). Yet, a closer look at the problem suggests that undermining the role of culture may be misleading.

We argue that existing research and practice erroneously identify culture with its observable artifacts and espoused values, while the deeper level culture and its basic underlying assumptions is frequently overlooked and yet remains to be explored (see the "onion skin" model of culture by Sergiovanni and Starratt, 1988). For instance, Ho Park and Ungson (1997) suggest that cultural distance among the partners plays a minimal role in a success rate of companies operating across the borders but observe that U.S.-Japanese ventures lasted longer that U.S.-U.S. ones. We argue that this may be explained by the long-term orientation of Japanese national culture (Hofstede, 1993) translated into their business practices implying building and maintaining close relationship among the partners. Peculiarities and patterns in communication reflect this deep-level, often unobservable and even not readily apparent to the insiders themselves, component of the culture. Previous research supports the importance of cross-cultural communication at both organizational and team levels. Managing cultural diversity, cultural differences, and cross-cultural conflicts has surfaced as frequent challenges for cross-cultural work environment (Marquardt and Hovarth, 2001). Because of their diverse perceptions, managers are more likely to interpret and respond differently to similar strategic issues or tasks (Schneider and DeMeyer, 199; Sousi, 2014) and exhibit specific managerial styles (Filippov, 2012; Radulescu and Tirla, 2014). Intercultural competence is thus an important component of a manager's ability to address any performance challenges (Gandolfi, 2012; Matveev, 2017; Matveev and Nelson, 2004; Milter, Matveev and Deselnicu, 2013; Yook, 2018). Hence, further understanding of the complex and multidimensional phenomenon of intercultural communication is warranted at all levels of the organization and in different cultural settings.

In this paper, we address the simultaneous effect of all three components of culture, ranging from the surface-level artifacts to the deep level of values and hidden assumptions (Sergiovanni and Starratt, 1988; 2006), in their relation to the effectiveness of cross-cultural communication and discuss the implications of employees' abilities to operate within each particular category. This study uses qualitative data from an insurance brokerage operating in five different cultural contexts. We deem the sample to be particularly relevant to the problem in focus. Not only our respondents deal with multiple cultures on a daily basis, but also the sheer surviving and success of this business is predetermined by zero miscommunication among its major players. We explore certain moderators within personality and demographic variables, such as the time vs. intensity of interaction with a foreign culture and active pursuing of understanding vs. passive acceptance 
of others. Finally, we discuss the identified themes in successful cross-cultural interactions and communication patterns that exhibit a high predictive power in regard to identifying, and, potentially, training culturally competent communicators.

\section{Theoretical background}

In the world of business and organizations, competence determines a person's ability to perform a required task effectively (Klemp, 1979). In multicultural organizations obtaining information from a colleague or performing a task requires a high degree of intercultural competence (Matveev, 2005, 2017). Scholars identified various individually-based characteristics that constitute intercultural competence, such as relationship skills, communication skills, and personality traits such as inquisitiveness (Black and Gregersen, 2000; Brancu, Munteanu \& Golet, 2016; Kealey and Protheroe, 1996; Mendenhall, 2001; Moosmüller, 1995). Scholars vary in their definition of intercultural competence depending on the contexts. While some focus on cultural awareness, knowledge, and motivation, others focus on adopted skills such as communication and behavioral skills (Byram, 1997; Spitzberg, 1983). Yet another group of researchers define intercultural competence with such dimensions as interpersonal skills, effectiveness, cultural uncertainty, and cultural empathy (Arasaratnam and Doerfel, 2005; Gudykunst, 1995; Matveev and Nelson, 2004; Van der Zee and Brinkmann, 2004).

National cultures can differ in many ways. For instance, team members from different cultures vary in their communication behaviour, their motivation for seeking and disclosing information, and their need to engage in self-categorization (Gudykunst, 1997). Team mebers from Western Europe (as from the United Kingdom) value intellectual autonomy, egalitarianism and harmony more than team members from Eastern or Southern Europe. Sagiv and Schwartz (2007) described Western Europe as the lowest on hierarchy and embeddedness. East European cultures stand higher on embeddedness and hierarchy compared with West European cultures. Furthermore, the Baltic and East-Central countries are higher in harmony, intellectual autonomy and egalitarianism and lower in mastery and hierarchy than the Balkan and most Eastern states (Sagiv and Schwartz, 2007).

Studying the role of communication in culture and distinguishing cultures and communication by the information surrounding an event regardless of the verbal message, Hall $(1976,1989)$ viewed cultures on a low-to-high context continuum. Low-context cultures use low levels of programmed information to provide context; the explicit code, the words, carry the message. The message eclipses the medium, words convey the information, and meaning is explicit. North America's task-centered communication, in which relatively little information is needed about a person or a company before business can be transacted, is a good example of low-context communication (Marquardt and Horvath, 2001). Highcontext cultures convey the message through non-verbal context; the physical setting and the individual's internalized values, beliefs, and norms convey the 
message (Hall, 1976, 1989). High-context cultures, such as Russian culture, share meaning implicitly. The listener knows the context and needs little background information (Hall, 1989). Communication and behavioral rules are implicit in the context. Communicators need rich contextual information about a person or a company before business transactions can be completed successfully (Marquardt \& Horvath, 2001). High-context cultures value face saving, group orientation and relationship that translate into covert communication patterns and affectiveintuitive style. Low-context cultures are more likely to use factual-inductive style in of communication (Ting-Toomey, 2012).

\section{Challenges of insurance business across cultures}

Insurance industry in the world is an important part of the economy with annual turnover of nearly USD 5 trillion, or $6.6 \%$ of the world's GDP. Every 15th Dollar produced in the world goes into insurance (Swiss Reinsurance Company, 2012). North America and Western Europe account for $62 \%$ of the world's insurance industry with an average share $7.94 \%$ of GDP. In Central and Eastern Europe insurance development and penetration is much lower. The region, which includes Russia and CIS countries, accounts for only $2 \%$ of the world's market and has a low penetration of $2.62 \%$ of GDP (Swiss Reinsurance Company, 2012).

Insurance does not exist in the vacuum and is tightly connected with the social and economic situation of a particular country. Philosophical understanding of life shapes the attitude towards life insurance, savings, retirement, and investment (Grishin, 2009). Insurance is about information. A Western insurer will not provide cover for an energy plant in the East unless he gets a clear picture of all safety and security arrangements in the plant. In the Eastern countries insurance companies are used to chase their clients who reluctantly provide information. In the West it is impossible to insure anything without information, and, therefore, the position of an insurance company is much more respectable. However, in the Eastern countries, the insured company is only obliged to provide information when directly asked by the insurer. For example, insurance companies report that they had to chase businesses in Russia, feeling that the later did not take insuring seriously (Grishin, 2009). Most likely this reluctance can be explained by some historical and cultural differences, including the differences in their perception of information value and communication styles.

In addition to complexity and cumbersome nature of oral communication and the legal regional peculiarities, written communication represents yet another problem. Russian written language is much more elaborate and, to a certain extent, more bureaucratic then English. The campaign for Crystal Clear English in the U.K. has produced visible effects (Grishin, 2009). Our contact company used to work with an insurance manager, a former interpreter from Russia, who just loved replacing simple words by more sophisticated-sounding. As a result, English colleagues used to show their bi-lingual manager a text written by this gentleman, asking, what exactly he meant by that. One of the e-mails was analyzed using the 
Text Fogginess index, which looks at the number of more than three-syllable words and the average length of a sentence. The message showed an index more acceptable for a scientific article, then for a business letter. We argue that the person was a typical representative of its culture, demonstrating high preference to the communication style that he deemed deserving the highest recognition as the most appropriate (Grishin, 2009).

Communication skills can shape intercultural understanding of the context and alleviate the "lost in translation" problem. For example, an insurance contract in Russia or in the Ukraine, especially, in corporate insurance, is a very lengthy document, numbering 10 to 15 pages. A London market main insurance document, used to be called a Cover-note, is usually 2 to 3 pages long and is very clearly structured. A recent form of the Reformed Market Contract is also clear-cut and is usually not more than 5-8 pages long. Experience in working with the British Cover-notes helps insurance brokers formulate more precisely which information they need to obtain from their Eastern and Southern counterparts (Grishin, 2000). We maintain that this example demonstrates the difference between these cultures - the High-context Ukraine vs. Low-context U.K. cultural values, and their covert vs. factual-inductive styles (Ting-Toomey, 2012).

\section{Organizational context}

Focusing on the Eurasia markets, we define "Western European Countries" as those that include countries in the European Union dated to the year 2000. We label "Eastern European Countries" as those that include the Central European and the former Soviet Union countries and "South European Countries" as those that include the Mediterranean countries (Greece, Turkey, etc.) and, to a certain extent, Spain and Italy.

Insurance and reinsurance broker's task is to liaise those who need insurance protection and those who can provide it. Oakeshott Insurance Consultants, an English insurance and reinsurance broker, was set up in London in 1993 by a Russian professional. Since then Oakeshott Insurance Consultants has grown to establish owned and affiliated offices in Moscow and St Petersburg, Russia, Kiev, the Ukraine, Almaty, Kazakhstan and in Denia, Spain. The founder of Oakeshott Insurance Consultants started in marine insurance, positioning itself as a specialist in finding solutions in the Western Europe for companies based in the East. For instance, its first client was a Lithuanian shipping company which was insured via Oakeshott Insurance Consultants in London. Later on, the company progressed to doing reverse contracts, insuring Western or South European companies in the East. An example would be insuring Greek or Turkish ship owners in Moscow. Nowadays a Lithuanian ship-owner prefers to buy a combined insurance cover with some risks in respect to his fleet insured with Lloyd's of London and others with a Russian insurer. Oakeshott Insurance Consultants has always stressed its task is to remove the East-West divide and to help to create a unified pan-European insurance market without boundaries 
(Grishin, 2000, 2009). At the present time Oakeshott Insurance Consultants is a group of companies based in four countries, i.e. England, Ukraine, Kazakhstan and Spain and employing 15 individuals, including 4 English, 4 Russians, 5 Ukrainians and 3 Kazakhs. The economic and cultural revolution of 1990ies diminished the stark differences in the ways of life among people in the Western, Eastern and Southern European countries. However, some linguistic, management and legal issues still separate not only these three regions, but also the states within each.

\section{Method}

We conducted interviews with individuals employed by a British insurance company in its two offices: in London, the U.K., and in Kiev, the Ukraine. Participation was sought from personal contacts in this organization. 8 employees participated in the study, which translates into an $80 \%$ response rate. Noteworthy, no potential informant contacted refused to participate, however, we approached only the full time employees who were physically present at work during data collection. Gender composition of the sample was $37 \%$ female and $63 \%$ male. The mean age of participants was 32 years old. On average, the subjects' tenure with the company ranged from one year and two months to 17 years and averaged 7 years.

We carried out semi-structured interviews with each participant, and combined those with the assessment of employee's intercultural competence provided by their managers. We assured the employees of complete confidentiality of their voluntary responses. The interviews ranged over multiple aspects of the employees' role, attitudes and behaviours related to cross-cultural communication. We asked the subjects to describe an event resulting in unsuccessful communication with an insurance company, a broker or an insured client from Russia. We were interested in the respondents' opinion in regards to the cause of this misunderstanding and the resolution achieved. We emphasized that we were particularly interested in personal experience and cases of interpersonal communication, rather than in cases that were sold via lawyers or at the company level. We were also asking about their motivation, preferred leadership style and their perception of the best way to convince people. The interview concluded with questions related to the company, such as support provided for overseas assignments and some demographical questions. After the analysis was complete, the company and its employees were provided with a brief report of the findings. This included aggregate findings and did not identify individuals in any way.

A qualitative approach was used to explore a complex and multidimensional nature of intercultural communication (Matveev, 2016). Semistructured interviews allowed us to frame the topic while probing for additional information (Miles and Huberman, 1994). Transcripts of the interviews were coded using the thematic analysis approach (Braun and Clark, 2006). Two graduate research assistants, blind to the purpose of the study, open-coded the data. Principal investigators identified the common responses and, consequently, used them as 
categories. We identified three major categories seen as problems in cross-cultural communication in multinationals: language, different legislation and context awareness. Then, we assessed the strength of each emergent category on the range from weak to strong. This differentiation was based on how frequently the category was used, how emphatically the respondent was describing it, and how much weight or importance the respondent was assigning to the category. Further analysis addressed the implications of operating within particular category vs. style flexibility to the effective and non-effective communication.

\section{Results}

We found the difference in legal environment and practices representing an equally relevant problem for both the British and the Ukrainian offices dealing with clients in Russia. Furthermore, the Ukrainian brokers experienced even more stress because they had to deal with three unique legal systems, a solution (intuitively or conscientiously) based on the high power distance of Russians (Hofstede, 1993) and on their assumption that British law system outplays the Russian one was developed:

Our main partners in Russia are insurance and reinsurance companies. When we deal with them on the reinsurance of different kind of risks, we have a lot of debate about jurisdiction of disputes and applicable law. Applicable law is one of the key points in the settlement of losses for both parties of contract, so everyone is trying to apply more favorable conditions for themselves. For instance we have original contract, which is based on the Kazakhstan legislation, and then we place this risk with Russian reinsurer. In these latter days quite often a lot of Russian reinsurers insist on using the Russian legislation in order to avoid any differences with their further reinsurance treaties. In such a case it is difficult to find a middle ground with both parties, because Original Insurer / Cedent insists on the implementation of legislation which is similar with the original contract, that would also avoid any problems with their Client. Often we solve such disputes because one of the parties adopts the law of the other party. In other cases, we propose to use English law as the jurisdiction of the settlement of disputes, as frequent practice of conclusion of international contracts.

While good employees see it as the "lost in translation" scenario when "we believe we understand one thing from say an underwriter and this turns out to mean something completely different," the more effective ones reflect on the differences and suggest a solution. For example, one of the British employees, a native English speaker, said:

What I have learnt is that you have to take special care that you completely understand what somebody for whom English is a second language is trying to express to you. The trick is to be patient and understanding and to broach the subject of asking the Underwriter to repeat their point in easier terms for you to understand in an apologetic and sympathetic manner. 
Ukrainian interviewees also recognized the importance of language. As one of Kiev office employees stated:

I cannot remember any misunderstanding or unsuccessful communication with Russian-speaking insurance professionals, be it in Russia, Latvia or Germany. I think because we have the same mentality and we speak one language.

We contend that in the hierarchy of the categories, awareness of the cultural context represents a higher level of intercultural skill and abilities. In Paige and colleagues' classification, this category corresponds to the highest level of intercultural sensitivity (2003). We reason that people with highly developed intercultural communication skills and people highly effective in multicultural setting can identify the source of the problem rather than simply stating its existence. In support to this idea, we found that employees who were characterized as effective intercultural communicators were indeed capable of framing the problems as contextual. They referred to the historical roots of the difference and to the cultural values, while identifying the hidden basic assumptions prevalent in the different culture. For instance, one of the respondents noted:

We are able to understand the stringent bureaucracy that often exists in Russia, particularly with the payment of claims and release of currency. This means we can pre-empt many requests for documentation that would not usually be made in, say, the London market. The result of this is increased efficiency in the claims process. On the other hand, we have tried to educate our Russian insurers about the processes that take place in the London market on claims payment, which we hope will enable them to adapt their processes in a way that would enable them to compete in the international market.

Another interviewee from the British office explains a different way of resolving a difficult situation caused by the orthogonal legal regulations in two different countries. We believe this explanation strongly relates to the hidden basic assumption of the importance of building personal relationship in the Russian culture and the value of affective communication style:

It would be unprofessional of me to say what we did exactly, but to cut a long story short we settled this issue ... partially because I travelled to Russia and met with the underwriter and established a personal relationship...

As evident from the examples, common behaviour patterns can be identified in the cases when a problem was resolved positively or when the employees actively search for an opportunity to establish the common ground and exhibit readiness for a shift in own mental models. In Table 1 we summarize our key findings and provide the evidence for each category and note our sense of the strength of the evidence. This serves as a qualitative conclusion resultant from a comprehensive discussion between the authors. Our analysis focused on consistency, clarity, quality and quantity of the evidence support. In addition, we considered existence and intensity of any disconfirming evidence. In the following section we elaborate on the evidence grouped by relevant categories and provide further details on these findings. The themes range from most to least obvious. 
Table 1: Key findings supporting evidence and their strength

\begin{tabular}{|c|c|c|}
\hline Theme & Nature of Evidence & $\begin{array}{l}\text { Strength } \\
\text { of Evidence* }\end{array}$ \\
\hline $\begin{array}{l}\text { Difference in the } \\
\text { legal environment }\end{array}$ & $\begin{array}{l}\text { Most employees were quick to point out at the } \\
\text { major difficulties experienced by insurance } \\
\text { business due to the difference in the law in the } \\
\text { countries of operation. This issue was found to be } \\
\text { equally relevant for British and Ukrainian offices } \\
\text { dealing with Russia. Further, Ukrainian brokers } \\
\text { experienced even more stress because they had to } \\
\text { deal with three unique legal systems: their own, } \\
\text { their mother company in London and the Russian } \\
\text { system. }\end{array}$ & $\begin{array}{l}\text { High quantity, } \\
\text { medium } \\
\text { intensity/ High } \\
\text { quantity, high } \\
\text { intensity }\end{array}$ \\
\hline $\begin{array}{l}\text { Language problem: } \\
\text { English as a second } \\
\text { language }\end{array}$ & $\begin{array}{l}\text { Virtually every interviewee stressed the } \\
\text { importance of finding the common language. For } \\
\text { British employees the essence of the problem lays } \\
\text { in the fact that English is the second language for } \\
\text { their Russian partners and clients. While good } \\
\text { employees simply recognized the problem, the } \\
\text { best ones tend to come up with a solution, often } \\
\text { very relevant and effective. The Ukrainian } \\
\text { interviewees also identified language as an } \\
\text { important contributor to the effectiveness of } \\
\text { communication and emphasized the benefits of } \\
\text { speaking fluent Russian. }\end{array}$ & $\begin{array}{l}\text { High quantity, } \\
\text { medium } \\
\text { intensity/ } \\
\text { High quantity, } \\
\text { high intensity }\end{array}$ \\
\hline $\begin{array}{l}\text { Cultural context } \\
\text { awareness: The } \\
\text { ability to go } \\
\text { beyond an evident } \\
\text { explanation; } \\
\text { readiness to ask } \\
\text { "why so" and } \\
\text { ability to shift the } \\
\text { communicative } \\
\text { style and the frame } \\
\text { of reference }\end{array}$ & $\begin{array}{l}\text { Regardless of the country of origin, the most } \\
\text { effective communicators were able to identify the } \\
\text { context and to appreciate its critical role. They } \\
\text { referred to the historical roots of the difference, to } \\
\text { cultural values and some were capable of } \\
\text { identifying the hidden basic assumptions } \\
\text { prevalent in the different culture. Furthermore, the } \\
\text { highly effective individuals adapted their behavior } \\
\text { and company practices based on these contextual } \\
\text { factors. Finally, they demonstrated a capability to } \\
\text { switch between the communication styles as } \\
\text { needed, without being "stuck" with the typical } \\
\text { style of their national culture. }\end{array}$ & $\begin{array}{l}\text { Low quantity, } \\
\text { low intensity } \\
\text { /Medium } \\
\text { quantity, high } \\
\text { intensity }\end{array}$ \\
\hline
\end{tabular}

*The assessment is provided for the moderately effective vs. highly effective cross-cultural communicators

\section{Discussion}

Our study explored the problems that multinational companies face when dealing with cultures that are strikingly different from a mother-culture of their company in the legislative, economic and cultural aspects. Specifically, we focused on the peculiarities of cross-cultural communication and on the traits and 
behaviours that distinguished more effective employees from less effective ones. We identified three common themes "responsible" for miscommunication in a global insurance company: language, legal environment and cultural context awareness. Using the theme analysis we identified critical differences in the attitudes, behaviour and demographics that explain successful cross-cultural communication between the home office and the subsidiary of a global company.

We identified three major themes in our interviews that asked to recall cases of miscommunication (see Table 1). We maintained that after a certain number of years in the industry it is relatively easy to see the difference in the legal environment of the countries of operation. We also confirmed the need for foreign language proficiency. Thus, in addition to identifying the major themes, we aimed at answering the question of what behavioral or demographic differences can explain higher crosscultural effectiveness or a lack of thereof. We elaborated on the research that argues for a holistic and context sensitive approach to the use of language in multilingual organizations (Angouri and Piekkari, 2017) and demonstrated that there is a difference among good and best employee in the perceived intensity of the language and context problem and in their approaches to correct it.

Researchers often explore the correlation between intercultural competence and the length of the exposure to a different culture. The criteria of the number of years abroad is often used a proxy for predicted expatriate success (Francesco and Gold, 2005). Interestingly, we were unable to confirm this: the employees with longer multinational company tenure were not found to be the most successful in their cross-cultural communication. A plausible explanation of the higher level of intercultural competence is suggested to be in the level of education moderated by the local vs. global experience and its intensity. This finding supports earlier findings in the literature that proposes the degrees of interactions leading to acquiring a multi-cultural perspective (Myers, 2009). Our study identified a strong correlation between these degrees, ranging from occasional exposure to a different culture to emergence into a different culture when obtaining a degree abroad or getting married to a foreigner. While such differentiation is interesting on its own, we admit that the exact causality of this relationship is yet to be established.

We found that the source of intercultural competence does not emerge from the number of years spent in the multicultural environment, but rather from the "inward" versus "outward" orientation in dealing with a foreign culture. Specifically, more culturally adept people were actively seeking a different cultural experience. They intentionally set to explore the foreign culture and were open to its artifacts such as food, sports and ways people spend their leisure time. This phenomenon echoes Chang and colleagues' finding on the role of opportunity seeking: expatriates who were deliberate and active in establishing relationships with locals were found to successfully facilitate knowledge transfer (Chang, Gong and Peng, 2012). This "outward" orientation differentiates them from less culturally adept "inwardly oriented" individuals, who tend to build the crosscultural interactions around their own culture and their own culturally specific understanding of what is good and appropriate. Noteworthy, these individual are 
not necessarily ego-centric or homophobic. They are relatively open-minded and often are aware of the cultural differences and do not reject them. What sets them apart is that they are not actively looking for a different experience and, if they face such experience, they do not embrace it or build upon it. For instance, a person who is a fan of soccer would not be interested in talking about other sports and would never initiate an interaction with a hockey fan. By the same token, they will not try or appreciate food from a different culture, although they would not necessarily openly declare that their food is better. In other words, they do not seem ready to shift their frame of reference and embrace the point of view of another person coming from a different cultural background.

We observed a similar pattern in the communication style flexibility domain. We found that the most effective employees used culturally appropriate communication styles regardless of their original cultural styles. While the most culturally adept communicators chose both affective and factual styles, the less effective employees were limited to the communication style of their own culture covert and affective in the Ukrainian sample and factual-inductive in the British sample. Our findings support previous research that demonstrated that being aware of the cultural differences does not preclude from cultural inefficiency unless a deliberate effort is made to accept those as fully "legitimate", embrace them and act accordingly. For instance, Jonasson and Lauring explain how a group of Danish expatriates intentionally avoided flexibility in communication: "while well aware of the tendency of the Chinese to communicate in a high-context fashion, the expatriate managers described such communication practices as excluding equal dialogue and reacted by using one-way communication." (2012, p. 413). Essentially, they ignored the potential for being flexible in communicating with their local peers on the management team, and "chose to blame cultural differences for any communication problems" (Jonasson and Lauring, 2012, p. 413). This resulted in fragmentation of the managers into two groups with separate identities, limiting their opportunity for collaboration and mutual satisfaction.

Finally, this study demonstrates certain universality of traits and behaviours among effective cross-cultural communicators. Despite the fact that the United Kingdom and the Ukraine are very different in their national cultures, we found the cross-cultural communication styles and behaviours of effective employees in the U.K. and the Ukraine to be very similar. In fact, both the U.K. and the Ukrainian employees listed similar typical problems and emphasized the importance of context awareness. Similarly, literature suggests striking alikeness of effective leaders across the globe. For instance, an international comparative study of successful women in South Africa and successful women in the Americas suggested no significant difference in their personality and cultural characteristics (Doubell \& Struwig, 2016), and no cultural differences were found to be a contextual factor influencing conflict behaviour in top management teams in Austria and Slovenia (Sternand and Schwarz-Musch, 2014). Further research will need to further investigate behaviours of highly effective crosscultural communicators. 


\section{Implications for business and research}

This study has multiple practical implications. First, it contributes to our understanding of traits and behaviours of effective cross-cultural communicators that helps identify and train interculturally competent communicators. Second, we argue that preference should be given to the employees who actively seek different cultural experiences, demonstrate readiness to shift their frame of reference and exhibit flexibility in their communicative styles. Third, we argue that the widely used criteria of the length or frequency of cross-cultural encounters should be used with caution as it is not a proxy of intercultural success. Finally, fluency in a foreign language represents an important but not self-exhaustive factor in effective cross-cultural interactions.

This study has some limitations. First is the focus on one company in one particular industry. While Oakeshott Insurance Consultants is a great example of a successful global company navigating the cross-cultural terrain in five diverse countries, it is rather impossible to claim generalizability of the findings to other companies or different industry. A larger sample would be necessary to arrive at stronger conclusions. The second limitation is our focus on surveying employees and managers from the company's head office in the U.K. and the regional office in the Ukraine. Surveying employees and managers from other offices would certainly enrich the data and provide more rich content for the qualitative analysis. The third limitation is the time-fixed or cross-sectional nature of the study. A longitudinal study would provide an opportunity to study the same organization at different times and minimize the data noise such as task complexity, seasonality and task urgency. Finally, further in-depth analysis of data from the U.K. and the Ukraine can yield additional themes and provide a finer explanation of the multifaceted culture-communication-relationship and cross-cultural effectiveness in multinational organizations.

\section{Conclusion}

This study aims at identifying conditions of successful cross-cultural interactions and communication patterns of interculturally competent communicators. It adds to our understanding of the role of contextual variables such as length vs. intensity of interaction with a foreign culture and active pursuing of understanding a foreign culture vs. passive acceptance of others. The qualitative analysis of rich interview data from Oakeshott Insurance Consultants yielded some critical insights on the legal environment, linguistic barriers, and cultural context awareness as the key focus areas among these numerous challenges. In multinational insurance organizations, as in other industries, the challenges of cross-cultural communication among regional offices and clients are enormous. Thus, insurance executives and brokers are recommended to implement the findings to ensure successful business operation across cultures. The practical implication extends to hiring and personnel development in a MNC.

Review of International Comparative Management

Volume 20, Issue 3, July 2019 


\section{References}

1. Angouri, J. \& Piekkari, R., 2017. Organising multilingually: Setting an agenda for studying language at work. European Journal of International Management, 12(1-2), pp. 8-27.

2. Arasaratnam, L.A., \& Doerfel, M.L., 2005. Intercultural communication competence: Identifying key components from multicultural perspectives. International Journal of Intercultural Relations, 29(2), pp. 137-63.

3. Black, J.S., \& Gregersen, H.B., 2000. The right way to manage expats. In Garten, J.E. (Ed.), Worldview: Global strategies for the new economy, pp. 187200. Boston, MA: Harvard Business School Press.

4. Brancu, L., Munteanu, V. \& Golet, I., 2016. A Comparative Approach of Cultural Intelligence Profile of Management and Non-Management Romanian Students. Review of International Comparative Management, 17(4), pp.308-319.

5. Braun, V. \& Clark, V., 2006. Using thematic analysis in psychology. Qualitative Research in Psychology, 3, pp. 77-101.

6. Byram, M., 1997. Teaching and assessing intercultural communicative competence. Clevedon: Multilingual Maters LTD.

7. Chang, Y.Y., Gong, Y. \& Peng, M.W., 2012. Expatriate knowledge transfer, subsidiary absorptive capacity, and subsidiary performance. Academy of Management Journal, 55(4), pp. 927-948.

8. Doubell, M. \& Struwig, M., 2016. A study of personality and cultural characteristics of successful women: An international comparative analysis. Journal of Management \& World Business Research, 13(1), pp. 1-12.

9. Filippov, S., 2012. Emerging Russian multinational companies: Managerial and corporate challenges. European Journal of International Management, 6(3), pp. 323-341.

10. Francesco, A.M. \& Gold, B. A., 2005. International organizational behavior: Text, cases, and skills. Upper Saddle River, NJ: Prentice Hall.

11. Gandolfi, F., 2012. A Conceptual Discussion of Transformational Leadership and Intercultural Competence. Review of International Comparative Management, 13(4), pp. 522-534.

12. Grishin, G.V., 2000. Sailing far into the ocean: An insurance is a must. Moscow, Russia: RUID.

13. Grishin, G.V., 2009. Let's talk. Almaty, Kazakhstan: Edelweiss.

14. Gudykunst, W.B., 1995. Anxiety/uncertainty management (AUM) theory. In Wiseman R.L. (Ed.), Intercultural Communication Theory, pp. 8-85. Thousand Oaks, CA: Sage Publications.

15. Gudykunst, W.B., 1997. Cultural variability in communication. Communication Research, 24(4), pp. 327-348.

16. Hall, E.T., 1976. Beyond culture. Garden City, NY: Anchor Press.

17. Hall, E.T., 1989. The dance of life: The other dimension of time. New York:

$238 \quad$ Volume 20, Issue 3, July $2019 \quad$ Review of International Comparative Management 
Doubleday.

18. Hofstede, G., 1993. Cultural constraints in management theories. The Executive, 7(1), pp. 81-94.

19. Ho Park, S.H. \& Ungson, G.R., 1997. The effect of national culture, organizational complementarity, and economic motivation on joint venture dissolution. Academy of Management Journal, 40(2), pp. 279- 307.

20. Jonasson, C. \& Lauring, J., 2012. Cultural differences in use: The power to essentialize communication styles. Journal of Communication Management, 16 (4), pp. 405-419.

21. Kealey, D.J. \& Protheroe, D.R., 1996. The effectiveness of cross-cultural training for expatriates: An assessment of the literature on the issue. International Journal of Intercultural Relations, 20(2), pp. 141-165.

22. Klemp, Jr., G.O., 1979. Identifying, measuring and integrating competence. In Pottinger P.S. and \& Goldsmith J. (Eds.), New directions for experiential learning: Defining and measuring competence, pp.41-52. San Francisco, CA: Jossey-Bass.

23. Matveev, A.V., 2005. Making multicultural teams work: A practitioner's advice for improving multicultural team effectiveness. The International Journal of Knowledge, Culture and Change Management, 4, pp. 713-718.

24. Matveev, A.V., 2016. Applying multiple research methods in intercultural research: A study of intercultural communication competence in Russia. In Jia W. (Ed.), Intercultural communication: Adapting to emerging global realities, pp. 107-118. San Diego, CA: Cognella, Inc.

25. Matveev, A.V., 2017. Intercultural competence in organizations: A guide for leaders, educators and team players. Management for Professionals Series. New York: Springer Science \& Business and Media Group.

26. Matveev, A.V. \& Nelson, P.E., 2004. Cross cultural communication competence and multicultural team performance: Perceptions of American and Russian managers. International Journal of Cross Cultural Management, 4(2), pp. 253-70.

27. Marquardt, M.J. \& Horvath, L., 2001. Global teams: How top multinationals span boundaries and cultures with high-speed teamwork. Palo Alto, CA: Davies-Black.

28. Mendenhall, M.E., 2001. New perspectives on expatriate adjustment and its relationship to global leadership development. In Mendenhall, M.W., Torsten, M.K. and Günter K.S. (Eds.), Developing global business leaders: Policies, processes, and innovations, pp. 1-18. Westport, CT: Quorum Books.

29. Milter, R.G., Matveev, A.V. \& Deselnicu, D.C., 2013. Impact of multicultural competence for teams addressing strategic challenges: A training and development model. Journal of Management \& World Business Research, 10(1), pp. 39-47.

30. Moosmüller, A., 1995. Learning objectives in intercultural competence: Decoding German everyday knowledge from a Japanese perspective, in Jensen,

\begin{tabular}{llr}
\hline Review of International Comparative Management & Volume 20, Issue 3, July 2019 & 239
\end{tabular} 
A. Jaeger, K. and Lorentsen, A. (Eds.) Intercultural Competence, 2, pp. 191-207. Aalborg: Aalborg University Press.

31. Myers, D.G., 2009. Social psychology. McGraw-Hill.

32. Miles, M. \& Huberman, A., 1994. Qualitative data analysis. Thousand Oaks, CA: Sage.

33. Paige, R.M., Jacobs-Cassuto, M. \& Yershova, Y., 2003. Assessing intercultural sensitivity: an empirical analysis of the Hammer and Bennett Intercultural Development Inventory. International Journal of Intercultural Relations, 27(4), pp. 467-486.

34. Pothukuchi, V., et al. 2002. National and organizational culture differences and international joint venture performance. Journal of International Business Studies, 33(2), pp. 243-265.

35. Radulescu, R., \& Tirla, F. 2014. Guidelines in the Adaptation of Business Models to Different Markets in the Context of Globalization. Review of International Comparative Management, 15(4), pp. 479-486.

36. Sagiv, L. \& Schwartz, S.H., 2007. Cultural values in organisations: insights for Europe, European Journal of International Management, 1(3), pp.176-190.

37. Sergiovanni, T.J. \& Starratt, R.J., 1988. Supervision Human Perspectives $\left(4^{\text {th }}\right.$ ed.). New York: McGraw-Hill.

38. Sergiovanni, T.J. \& Starratt, R.J., 2006. Supervision: A Redefinition. New York: McGraw Hill.

39. Schneider, S.C. \& DeMeyer, A., 1991. Interpreting and responding to strategic issues: The impact of national culture. Strategic Management Journal, 12, pp. 307-320.

40. Sousi, N., 2015. Human Resources Management in the Syrian Companies in Romania. Review of International Comparative Management, 15(2), pp. 244-249.

41. Spitzberg, B.H., 1983. Communication competence as knowledge, skill and impression. Communication Education, 32, pp. 323-29.

42. Sternad, D. \& Schwarz-Musch, A., 2014. Conflict perceptions in top management teams: A cross-cultural study. European Journal of CrossCultural Competence and Management, 3(1), pp. 68-92.

43. Swiss Reinsurance Company. 2012. World insurance in 2011 shows non-life insurance premiums continued to grow in 2011 despite an overall decline in premiums. Sigma, 3, http://www.swissre.com/sigma/. [Accessed 10 May 2019].

44. Ting-Toomey, S., 2012. Communicating across cultures. Guilford Press.

45. Van der Zee, K.I. \& Brinkmann, U., 2004. Construct validity evidence for the intercultural readiness check against the multicultural personality questionnaire. International Journal of Selection and Assessment, 12(3), pp. 285-90.

46. Yook, E.E.L., 2018. Review of the book Intercultural Competence in Organizations: A Guide for Leaders, Educators and Team Players, by A.V. Matveev. International Journal of Cross Cultural Management, 18(1), pp. 105-108. 